7 Edwards R, Clague J, Gibson H, Helliwell T. Muscle metabolism, histopathology, and physiology in chronic fatigue syndrome. In: Straus S, ed. Chronic fatigue syndrome. New York: Marcel Dekker, 1994:241-61.

8 De Lorenzo F, Xiao H, Mukherjee M, Harcup J, Suleiman S, Kadziola Z, et al. Chronic fatigue syndrome: physical and cardiovascular deconditioning. O J Med 1998:91:475-81.

9 Wessely S, Hotopf M, Sharpe M. Chronic fatigue and its syndromes. Oxford: Oxford University Press, 1998

10 Sharpe M, Hawton K, Simkin S, Surway C, Hackmann A, Klimes I, et al. Cognitive behaviour therapy for the chronic fatigue syndrome: randomised controlled trial. BMJ 1996;312:22-6.

11 Deale A, Chalder T, Marks I, Wessely S. Cognitive behavioural therapy for chronic fatigue syndrome: a randomised controlled trial. Am J Psychiatry 1997:154:408-14.

12 Powell P, Edwards R, Bentall R. The treatment of wheelchairbound chronic fatigue syndrome patients: Two case studies of a pragmatic treatment approach. Behavioural and Cognitive Psychotherapy 1999;27:249-60.

13 Sharpe M, Archard L, Banarvala J, Borysiewicz L, Clare A, David A, et al. A report-chronic fatigue syndrome: guidelines for research. J $R$ Soc Med 1991;84:118-21.

14 Ware J, Sherbourne C. The MOS 36-item short form health survey (SF36). Med Care 1992;30:473-83.
15 Zigmond A, Snaith R. The hospital anxiety and depression scale. Acta Psychiatr Scand 1983;67:361-70.

16 Miller W, Rollnick S. Motivational interviewing. New York: Guilford Press, 1991.

17 Chalder T, Berelowitz G, Pawlikowska T, Watts L, Wessely S, Wright D, et al. Development of a fatigue scale. J Psychosom Res 1993:37:147-53.

18 Garratt A, Ruta D, Abdalla M, Buckingham J, Russell I. The SF36 health survey questionnaire: an outcome measure suitable for use within the NHS? BMJ 1993;306:1440-4

19 Jenkins D, Stanton B, Niemcryk S, Rose R. A scale for the estimation of sleep problems in clinical research. J Clin Epidemiol 1988;41:313-21.

20 Guy W. Clinical global impressions. In: ECDEU assessment manual for psychopharmacology. Rockville, MD: National Institute of Medical Health, 1976:218-22.

21 Wearden A, Morriss R, Mullis R, Strickland P, Pearson D, Appleby L, et al. Randomised, double-blind, placebo-controlled treatment trial of fluoxetine and graded exercise for chronic fatigue syndrome. Br J Psychiatry 1998;172:485-96.

22 Fulcher K, White P. Randomised controlled trial of graded exercise in patients with the chronic fatigue syndrome. BMJ 1997;314:1647-52.

23 Reid S, Chalder T, Cleare A, Hotopf M, Wessely S. Chronic fatigue syndrome. $B M J$ 2000;320:292-6.

(Accepted 17 November 2000)

\title{
Early childhood infectious diseases and the development of asthma up to school age: a birth cohort study
}

\author{
Sabina Illi, Erika von Mutius, Susanne Lau, Renate Bergmann, Bodo Niggemann, \\ Christine Sommerfeld, Ulrich Wahn, and the MAS Group
}

Editorial by

Johnston and

Openshaw

Department of

Pulmonology and

Allergology,

University

Children's Hospital,

Lindwurmstrasse 4,

80337 Munich,

Germany

Sabina Illi

research assistant

Erika von Mutius

head of asthma

outpatient clinic

Department of

Paediatric

Pneumology and

Immunology,

Charité, Humboldt

University,

Augustenburger

Platz 1, 13353

Berlin, Germany

Susanne Lau

research assistant,

paediatrician

Renate Bergmann

research assistant,

paediatrician

Bodo Niggemann

senior staff clinician

Christine

Sommerfeld

mathematician

Ulrich Wahn

head of department

Correspondence to:

Sabina Illi

sabina.illi@kk-i.med.

uni-muenchen.de

Members of the

MAS Group are

listed at the end of

the article

BMJ 2001;322:390-5

\begin{abstract}
Objective To investigate the association between early childhood infections and subsequent development of asthma.

Design Longitudinal birth cohort study.

Setting Five children's hospitals in five German cities.
\end{abstract}

Participants 1314 children born in 1990 followed from birth to the age of 7 years.

Main outcome measures Asthma and asthmatic symptoms assessed longitudinally by parental questionnaires; atopic sensitisation assessed longitudinally by determination of IgE concentrations to various allergens; bronchial hyperreactivity assessed by bronchial histamine challenge at age 7 years.

Results Compared with children with $\leqslant 1$ episode of runny nose before the age of 1 year, those with $\geqslant 2$ episodes were less likely to have a doctor's diagnosis of asthma at 7 years old (odds ratio 0.52 (95\% confidence interval 0.29 to 0.92$)$ ) or to have wheeze at 7 years old $(0.60$ (0.38 to 0.94$))$, and were less likely to be atopic before the age of 5 years. Similarly, having $\geqslant 1$ viral infection of the herpes type in the first 3 years of life was inversely associated with asthma at age 7 (odds ratio 0.48 (0.26 to 0.89)). Repeated lower respiratory tract infections in the first 3 years of life showed a positive association with wheeze up to the age of 7 years (odds ratio 3.37 (1.92 to 5.92) for $\geqslant 4$ infections $v \leqslant 3$ infections).

Conclusion Repeated viral infections other than lower respiratory tract infections early in life may reduce the risk of developing asthma up to school age.

\section{Introduction}

Strachan proposed a protective effect of infections on atopy by describing an inverse association between the number of older siblings and hay fever. ${ }^{1}$ This effect has since been confirmed using various markers of infectious burden such as number of older siblings, ${ }^{2-4}$ attendance at day care facilities, ${ }^{5}$ and positive serology to orofaecal infections. ${ }^{6} 7$ However, whether such a protective effect also operates for asthma remains unclear. Several authors have indeed reported that infections may enhance the development of asthma, particularly infections with respiratory syncytial virus. $^{8}{ }^{9}$

A German birth cohort recruited to the longitudinal multicentre allergy study (MAS) presented an opportunity to investigate prospectively the association between different types of early childhood infections and the subsequent development of asthma.

\section{Participants and methods}

\section{Study population}

The MAS Group recruited 499 newborn infants with risk factors for atopy (elevated cord blood $\operatorname{IgE}(\geqslant 0.9$ $\mathrm{kU} / \mathrm{l}$ ) or at least two atopic family members) and 815 newborn infants without these risk factors. ${ }^{10}$ The cohort children were followed up at the age of 1, 3, 6, 12 , and 18 months, and from then on at yearly intervals within 3 months of the child's birthday up to the age of 7 years. The study was approved by the local ethics committees.

\section{Respiratory symptoms}

At each follow up, parents gave structured interviews to a study doctor on their child's development. Of greatest interest was asthmatic and atopic symptoms and diseases. Among other questions, parents were asked whether their child had had "a wheezy or whistling noise while breathing" since the previous follow up. When the children were 7 years old parents 
were asked whether their child had ever had a diagnosis of asthma.

\section{Early childhood infectious diseases}

We also assessed other illnesses at each follow up. If the parents responded affirmatively to the question "Was your child ill since your last visit?" the interviewing doctor assessed the reported symptoms and diagnosis of the illness and encoded them according to the Weidtman code, a German language version of the ICD-9 (international classification of diseases, ninth revision) for paediatric use. ${ }^{11}$ In addition, we assessed any drugs the children were given. To keep reporting bias low, we asked the parents to keep a non-structured diary of their child's diseases, which served as memory aid for the interview. By the time the children were 3 years old, we had recorded 598 different Weidtman codes during the follow up visits, comprising 106 codes for infections.

Because of a potential bias attributable to reverse causation, we analysed separately all lower respiratory tract infections irrespective of the infectious agent (pneumonia, bronchitis, pertussis, tracheobronchitis, flu, croup, bronchiolitis). We combined all other codes to assess the effect of the overall burden of infectious diseases and, in a second step, separated them into several distinct categories: viral infections (measles, rubella, mumps, hepatitis $\mathrm{A}$ and $\mathrm{B}$, mononucleosis, runny nose (rhinitis), herpes, varicella, exanthema subitum, stomatitis, choriomeningitis, coxsackievirus); bacterial infections (meningitis, tonsillitis, lymphadenitis, otitis media, scarlet fever, septicaemia, abscess, impetigo, pyoderma, tuberculosis, urinary tract infections); fungal infections (nappy rash, candida infection); gastrointestinal infections (gastroenteritis, diarrhoea); and fever of unknown origin.

In addition, we assessed the number of antibiotic courses the children had received. Only antibiotic courses not related to the treatment of lower respiratory tract infections were included in statistical analysis.

\section{Antibodies to specific antigens}

We asked the parents to consent to blood sampling of their child at the ages of 1, 2, 3, 5, 6, and 7 years. We determined IgE concentrations to nine allergens (cow's milk, egg white, soya bean, wheat, house dust mite Dermatophagoides pteronyssinus, cat, dog, mixed grass pollen, and birch pollen) by CAP-RAST FEIA (Pharmacia and Upjohn, Freiburg, Germany). We defined sensitisation to a specific allergen as a concentration of $\geqslant 0.35 \mathrm{kU} / \mathrm{l}$ of the specific IgE.

\section{Bronchial challenge}

When the children were 7 years old we performed bronchial challenge, starting with $0.5 \mathrm{mg}$ histamine $/ \mathrm{ml}$ and increasing up to $8.0 \mathrm{mg} / \mathrm{ml}$ according to a standard procedure. ${ }^{12}$ We defined bronchial hyperreactivity as a $\mathrm{PC}_{20} \mathrm{FEV}_{1}$ (provocative concentration causing a $20 \%$ fall in forced expiratory volume in one second) greater than the 90th centile of the distribution of $\mathrm{PC}_{20} \mathrm{FEV}_{1}$ in a healthy subsample. ${ }^{13}$

\section{Statistical analyses}

We used $\chi^{2}$ tests to compare prevalences between groups and Mantel-Haenszel tests for analysing trends across categories. We calculated multivariate logistic regression models to analyse the effect of early childhood infectious diseases on asthma at the age of 7 years. For the longitudinal analyses, we used generalised estimation equation models to adjust for repeated measures. In order to take the stratified sampling scheme into account and to assess participation bias and potential effect modification, we initially stratified all multivariate analyses for elevated cord blood IgE concentration, family history of atopy, parental smoking at birth, and social status (defined as low, middle, or high parental education). If the results were similar over strata, however, we calculated the multivariate models in the total sample with indicator variables included for high risk of atopy at birth (elevated cord blood IgE concentration or two or more atopic family members), parental smoking at birth, and parental education. We also adjusted the longitudinal models for age. We used SAS software (version 6.12) for all statistical analyses.

\section{Results}

\section{Response rates}

Of the 1314 children in the MAS birth cohort, 1120 $(85 \%)$ participated in the follow up survey at 1 year old and $939(71 \%)$ participated in the final follow up

Table 1 Frequency of infectious diseases in first 3 years of life of 1314 children. Values are numbers (percentages)

\begin{tabular}{|c|c|c|}
\hline $\begin{array}{l}\text { No of episodes of infectious disease or } \\
\text { antibiotic treatment }\end{array}$ & First year of life & First 3 years of life \\
\hline \multicolumn{3}{|l|}{ Lower respiratory tract infections: } \\
\hline 0 & $950(72.3)$ & $620(47.2)$ \\
\hline 1 & $253(19.3)$ & $323(24.6)$ \\
\hline $2-7$ & $111(8.4)$ & $361(27.5)$ \\
\hline $8-14$ & 0 & $11(0.8)$ \\
\hline \multicolumn{3}{|l|}{ Viral infections: } \\
\hline 0 & $184(14.0)$ & $100(7.6)$ \\
\hline 1 & $303(23.1)$ & $105(8.0)$ \\
\hline $2-4$ & $679(51.7)$ & $400(30.4)$ \\
\hline $5-14$ & $148(11.3)$ & $684(52.1)$ \\
\hline $15-23$ & 0 & $25(1.9)$ \\
\hline \multicolumn{3}{|l|}{ Bacterial infections: } \\
\hline 0 & $1009(76.8)$ & $689(52.4)$ \\
\hline 1 & $221(16.8)$ & $313(23.8)$ \\
\hline $2-7$ & $84(6.4)$ & $298(22.7)$ \\
\hline 8-16 & 0 & $14(1.1)$ \\
\hline \multicolumn{3}{|l|}{ Fungal infections: } \\
\hline 0 & $789(60.0)$ & $664(50.5)$ \\
\hline 1 & $293(22.3)$ & $316(24.0)$ \\
\hline $2-9$ & $232(17.7)$ & $333(25.3)$ \\
\hline $10-15$ & 0 & $1(0.1)$ \\
\hline \multicolumn{3}{|l|}{ Gastrointestinal infections: } \\
\hline 0 & $914(69.6)$ & $547(41.6)$ \\
\hline 1 & $303(23.1)$ & $366(27.9)$ \\
\hline $2-5$ & $97(7.4)$ & $385(29.3)$ \\
\hline $6-8$ & 0 & $16(1.2)$ \\
\hline \multicolumn{3}{|l|}{ Fever due to infection of unknown type: } \\
\hline 0 & $1165(88.7)$ & $1004(76.4)$ \\
\hline $1-5$ & $149(11.3)$ & $310(23.6)$ \\
\hline \multicolumn{3}{|l|}{ Antibiotic courses*: } \\
\hline 0 & $933(71.0)$ & $559(42.5)$ \\
\hline 1 & $260(19.8)$ & $348(26.5)$ \\
\hline $2-7$ & $121(9.2)$ & $388(29.5)$ \\
\hline $8-14$ & 0 & $19(1.4)$ \\
\hline
\end{tabular}

*Excluding antibiotics given for lower respiratory tract infections. 
Table 2 Odds ratios ( $95 \%$ confidence intervals) ${ }^{*}$ of symptoms of asthma in 939 children at age 7 years according to infectious diseases acquired in first 3 years of life

\begin{tabular}{|c|c|c|c|c|}
\hline $\begin{array}{l}\text { No of episodes of } \\
\text { infectious disease or } \\
\text { antibiotic treatment }\end{array}$ & $\begin{array}{l}\text { No of } \\
\text { subjects }\end{array}$ & $\begin{array}{c}\text { Doctor ever } \\
\text { diagnosed asthma }\end{array}$ & Current wheeze & $\begin{array}{c}\text { Bronchial } \\
\text { hyperreactivity }\end{array}$ \\
\hline \multicolumn{5}{|l|}{$\begin{array}{l}\text { Lower respiratory tract } \\
\text { infections: }\end{array}$} \\
\hline$\leqslant 1$ & 704 & 1.00 & 1.00 & 1.00 \\
\hline $2-3$ & 169 & 1.32 (0.63 to 2.79$)$ & 1.62 (0.94 to 2.80$)$ & 1.19 (0.68 to 2.07$)$ \\
\hline$\geqslant 4$ & 66 & 4.46 (2.07 to 9.64$)$ & 3.97 (2.06 to 7.64$)$ & 2.14 (1.03 to 4.43$)$ \\
\hline \multicolumn{5}{|l|}{ Viral infections: } \\
\hline$\leqslant 1$ & 31 & 1.00 & 1.00 & 1.00 \\
\hline $2-4$ & 295 & $0.37(0.12$ to 1.11$)$ & 0.87 (0.28 to 2.69$)$ & 0.50 (0.19 to 1.34$)$ \\
\hline $5-7$ & 329 & 0.32 (0.10 to 0.95$)$ & 0.63 (0.20 to 1.97$)$ & $0.34(0.12$ to 0.91$)$ \\
\hline$\geqslant 8$ & 284 & $0.16(0.05$ to 0.54$)$ & 0.46 (0.14 to 1.49$)$ & 0.24 (0.09 to 0.68$)$ \\
\hline \multicolumn{5}{|l|}{ Bacterial infections: } \\
\hline$\leqslant 1$ & 672 & 1.00 & 1.00 & 1.00 \\
\hline$\geqslant 2$ & 267 & 1.10 (0.59 to 2.03$)$ & 0.81 (0.49 to 1.34$)$ & 1.11 (0.70 to 1.77$)$ \\
\hline \multicolumn{5}{|l|}{ Fungal infections: } \\
\hline$\leqslant 1$ & 660 & 1.00 & 1.00 & 1.00 \\
\hline$\geqslant 2$ & 279 & 0.98 (0.53 to 1.83$)$ & 1.30 (0.81 to 2.10$)$ & 1.71 (1.08 to 2.69$)$ \\
\hline \multicolumn{5}{|l|}{$\begin{array}{l}\text { Gastrointestinal } \\
\text { infections: }\end{array}$} \\
\hline$\leqslant 1$ & 591 & 1.00 & 1.00 & 1.00 \\
\hline$\geqslant 2$ & 348 & 0.85 (0.47 to 1.54$)$ & 0.97 (0.61 to 1.54$)$ & 0.69 (0.43 to 1.10$)$ \\
\hline \multicolumn{5}{|l|}{ Antibiotic coursest: } \\
\hline$\leqslant 1$ & 600 & 1.00 & 1.00 & 1.00 \\
\hline$\geqslant 2$ & 339 & 1.08 (0.59 to 1.99$)$ & $0.89(0.54$ to 1.45$)$ & 1.31 (0.83 to 2.08$)$ \\
\hline
\end{tabular}

${ }^{*}$ Adjusted for parental education, high risk of atopy at birth, and parental smoking at birth. †Excluding antibiotics given for lower respiratory tract infections.

survey at the age of 7 years. Participation rates were slightly lower for blood sampling $(724 / 1120(65 \%)$ at age 1 and 679/939 (72\%) at age 7) and for bronchial challenge at age $7(645 / 939(69 \%))$.

In order to assess potential participation bias, we compared children with respect to the number of missed follow up visits, using data collected at birth. Children with a parental history of atopy, higher level of parental education, or with no exposure to parental smoke participated significantly more often than children without the respective characteristic $(\mathrm{P}<0.001$ for trend). We found no significant differences with respect to child's sex, cord blood IgE concentration, or number of older siblings (data not shown).

\section{Early childhood infectious diseases}

Table 1 shows the frequencies of infectious diseases and of antibiotic treatment in the first three years of life as encoded by the study doctor. The commonest type of infectious disease was viral infection, with only 184 children (14\%) not having had a viral infection in the first year of life. Other types of infectious diseases were relatively rare in the first year of life.

\section{Association of early infectious diseases and asthma} at age 7

At 7 years old, 57 (6\%) of the 939 children who participated in the follow up survey had ever had a diagnosis of asthma and $94(10 \%)$ had current wheeze in the past 12 months. Furthermore, 105/645 (16\%) children were hyperresponsive to the histamine challenge, and 280/679 (41\%) were sensitised.

Lower respiratory tract infections-The number of lower respiratory tract infections in the first three years of life showed a strong positive dose-response relation with a doctor ever diagnosing asthma and with current wheeze and bronchial hyperreactivity at age 7 , the effect being strongest for $\geqslant 4$ lower respiratory tract infections (table 2). However, when we categorised lower respiratory tract infections in the first year of life as non-wheezing or wheezing (according to whether wheezing episodes occurred in the follow up period in which the infection occurred) we found that nonwheezing infections constituted only a non-significant risk for wheeze at the age of 7 years (odds ratio 1.87 $(95 \%$ confidence interval 0.90 to 3.87$)$ for $\geqslant 2$ non-wheezing infections $v$ no lower respiratory tract infection). In contrast, lower respiratory tract infections with wheezing showed a strong positive association (odds ratio 6.19 (2.17 to 17.63) for $\geqslant 2$ wheezing infections $v$ no infection).

Other infections-The total number of infectious diseases other than lower respiratory tract infections in the first three years of life was inversely related to a diagnosis of asthma by 7 years of age (odds ratio 0.31 ( 0.11 to 0.85 ) for $\geqslant 4$ infections $v \leqslant 3$ infections), to current wheeze at age $7(0.55(0.20$ to 1.48$))$, and to bronchial hyperreactivity at age $7(0.40(0.16$ to 1.01$))$. When we analysed separately the different types of infectious diseases only viral infections showed a significant negative association with asthma at the age of 7 (table 2). Bacterial, fungal, or gastrointestinal infections had no significant effect on asthma irrespective of the number of episodes or the time span analysed (that is, in the first year or first three years of life). The number of antibiotic courses also showed no association with asthma at age 7 . When we analysed urinary tract infections separately we again found no effect on asthma diagnosis (odds ratio $1.43(0.32$ to 6.46$))$.

Viral infections-Table 3 shows that the protective effect of viral infectious diseases was mainly due to two subgroups, runny nose and viral infections of the herpes type (exanthema subitum, herpes, stomatitis, varicella). The strongest effects on asthma diagnosis, current wheeze, and bronchial hyperreactivity at age 7 were for recurrent runny nose in the first year of life: the prevalence of current wheeze was $9 \%$ in the children with $\geqslant 2$ episodes of runny nose in their first year of life compared with $13 \%$ in those with $\leqslant 1$ episode $(\mathrm{P}=0.034)$. In our regression model adjusted for parental education, high risk of atopy at birth, and parental smoking at birth, a child with $\geqslant 2$ runny nose episodes was at half the risk of having asthma diagnosed by the age of 7 as were children with $\leqslant 1$ episode (odds ratio 0.52 (0.29 to 0.92$)$ ). When we analysed the number of herpes type infections early in life we found similar protective effects on a diagnosis of asthma and on current wheeze at age 7 . When we analysed measles infections separately we found that a diagnosis of asthma was less common in children who had had measles than in those who had not $(1 / 27(4 \%)$ $v 56 / 910(6 \%), \mathrm{P}=0.59)$, but the small number of measles cases meant the difference was not significant.

Association of early infectious diseases and wheeze longitudinally

Longitudinal analysis confirmed the strong negative association of viral infections with asthma at age 7 seen in the cross sectional analysis (figure). We found no significant association between bacterial, fungal, gastrointestinal, or urinary tract infections in the first year of life with wheeze at the age of $4,5,6$, or 7 years (data not 
shown). The positive association of repeated lower respiratory tract infections before the age of 3 with wheeze at the age of 7 was confirmed longitudinally for wheeze at age 4 (odds ratio 3.56 (2.08 to 6.08 ) for $\geqslant 4$ infections $v \leqslant 3$ infections), age 5 (3.12 (1.83 to 5.34)), age 6 (3.24 (1.90 to 5.56)), and age 7 (3.41 (1.95 to $5.95))$.

\section{Association of early infectious diseases and sensitisation}

Only recurrent runny nose showed an association with subsequent atopic sensitisation: children with $\geqslant 2$ episodes of runny nose in the first year of life had half the risk of those children with $\leqslant 1$ episode of being sensitised to inhalant allergens at the age of 1 year (odds ratio $0.46(0.28$ to 0.76$)$ ) or 3 years $(0.53$ (0.37 to $0.76)$ ). At the age of 5 years, however, this effect became non-significant. None of the other groups of infectious diseases showed similar effects or trends, nor did the number of antibiotic courses (data not shown).

\section{Stratified analyses}

When we stratified the study sample for potential confounders and effect modifiers (family history of atopy, high cord blood IgE concentrations at birth, parental education, older siblings, and parental smoking) we got similar results to those for the total sample with all multivariate analyses.

\section{Discussion}

In our study cohort repeated lower respiratory tract infections early in life were positively associated with subsequent development of asthma, wheeze, and bronchial hyperreactivity. In contrast, early episodes of other infections (particularly runny nose and viral infections of the herpes type) were inversely related to development of asthma and respiratory symptoms.

\section{Possible limitations of study}

We assessed infectious diseases early in life via parental reports, which raises the possibility of incorrect and incomplete reporting. However, a positive family history of atopy, a major predictor of a child developing asthma, showed no association with the total number of reported infectious diseases or with the number of runny nose episodes (data not shown).

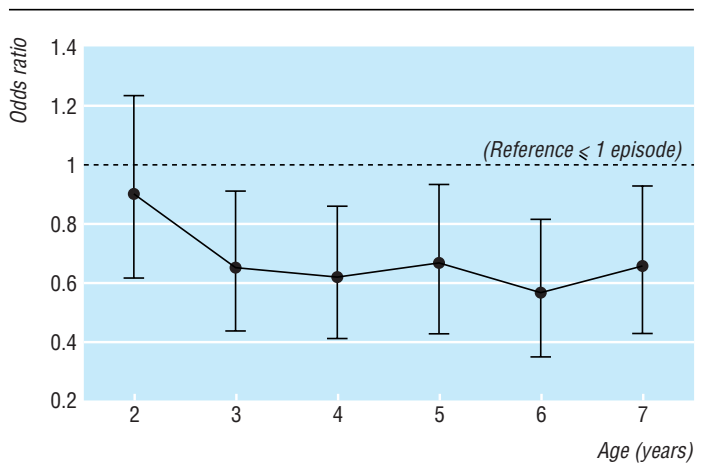

Longitudinal analysis of repeated episodes $(\geqslant 2)$ of runny nose in the first year of life and 12 month prevalences of wheeze up to the age of 7 years. Values are odds ratios with $95 \%$ confidence intervals adjusted for parental education, high risk of atopy at birth, parental smoking at birth, and age
Table 3 Odds ratios (95\% confidence intervals) ${ }^{*}$ of symptoms of asthma in 939 children at age 7 years according to viral infections acquired in the first years of life

\begin{tabular}{lcccc}
$\begin{array}{l}\text { No of episodes of } \\
\text { viral infection }\end{array}$ & $\begin{array}{c}\text { No of } \\
\text { subjects }\end{array}$ & $\begin{array}{c}\text { Doctor ever } \\
\text { diagnosed asthma }\end{array}$ & Current wheeze & $\begin{array}{c}\text { Bronchial } \\
\text { hyperreactivity }\end{array}$ \\
\hline In first year of life \\
\hline Runny nose: \\
\hline$\leqslant 1$ & 309 & 1.00 & 1.00 & 1.00 \\
\hline $2-3$ & 421 & $0.57(0.26$ to 1.23$)$ & $0.64(0.39$ to 1.05$)$ & $0.59(0.33$ to 1.04$)$ \\
\hline$\geqslant 4$ & 209 & $0.49(0.26$ to 0.94$)$ & $0.52(0.27$ to 0.98$)$ & $0.42(0.25$ to 0.70$)$ \\
\hline
\end{tabular}

\section{In first three years of life}

Runny nose:

\begin{tabular}{ccccc}
\hline$\leqslant 1$ & 67 & 1.00 & 1.00 & 1.00 \\
\hline $2-4$ & 348 & $0.60(0.24$ to 1.51$)$ & $0.82(0.36$ to 1.89$)$ & $0.41(0.20$ to 0.85$)$ \\
\hline $5-7$ & 304 & $0.48(0.18$ to 1.26$)$ & $0.71(0.30$ to 1.68$)$ & $0.33(0.15$ to 0.71$)$ \\
\hline$\geqslant 8$ & 220 & $0.37(0.13$ to 1.10$)$ & $0.62(0.25$ to 1.55$)$ & $0.25(0.11$ to 0.58$)$ \\
\hline
\end{tabular}

Viral infections of

herpes typet:

\begin{tabular}{|c|c|c|c|c|}
\hline 0 & 496 & 1.00 & 1.00 & 1.00 \\
\hline$\geqslant 1$ & 443 & $0.48(0.26$ to 0.89$)$ & 0.60 (0.38 to 0.94$)$ & 0.79 (0.51 to 1.22$)$ \\
\hline \multicolumn{5}{|c|}{ Measles infections: } \\
\hline 0 & 912 & 1.00 & 1.00 & 1.00 \\
\hline$\geqslant 1$ & 27 & 0.63 (0.08 to 4.84$)$ & $\ddagger$ & 0.78 (0.17 to 3.51$)$ \\
\hline \multicolumn{5}{|c|}{ Other viral infections§: } \\
\hline 0 & 882 & 1.00 & 1.00 & 1.00 \\
\hline$\geqslant 1$ & 57 & 1.51 (0.56 to 4.02$)$ & 0.86 (0.33 to 2.25$)$ & 1.01 (0.41 to 2.52) \\
\hline \multicolumn{5}{|c|}{$\begin{array}{l}\text { Viral infections of } \\
\text { unknown type: }\end{array}$} \\
\hline 0 & 883 & 1.00 & 1.00 & 1.00 \\
\hline$\geqslant 1$ & 56 & 0.53 (0.12 to 2.30$)$ & 0.27 (0.06 to 1.16$)$ & $0.13(0.02$ to 1.00$)$ \\
\hline
\end{tabular}

*Adjusted for parental education, high risk of atopy at birth, and parental smoking at birth.

†Varicella, herpes (zoster, febrilis, labialis), exanthema subitum, stomatitis.

‡Non-existent because no children with measles infection had current wheeze (compared with $10 \%$ of children without measles infection)

§Mumps, hepatitis A and B, coxsackievirus, Epstein-Barr virus, parvovirus, echovirus.

Hence, a differential reporting bias seems unlikely. Furthermore, the "hygiene hypothesis," first proposed by Strachan in $1989,{ }^{1}$ was of no major public interest at the time of the assessment of childhood illnesses. Confounding by increased awareness of illnesses by the parents or the interviewing doctors is thus improbable.

\section{Association of asthma with lower respiratory tract infections}

Repeated lower respiratory tract infections showed a strong positive association with subsequent wheeze and a doctor's diagnosis of asthma. Reverse causation seems a plausible explanation for this, with lower respiratory tract infections being predictors of rather than risk factors for asthma. Thus, children already predisposed to asthma might simply be more likely to develop symptoms of the lower respiratory tract when infected, rather than the virus causing the development of asthma. This explanation is supported by the frequency of repeated lower respiratory tract infections ( $\geqslant 2$ infections before age 3 ) being significantly higher in children with a family history of atopy than in those with no atopic family member $(81 / 270$ (30\%) $v$ $197 / 1035$ (19\%), $\mathrm{P}<0.0001)$.

When we categorised lower respiratory tract infections in the first year of life as wheezing or non-wheezing we found that non-wheezing infections had a non-significant negative association with atopic sensitisation at the age of 6 years (odds ratio $0.60(95 \%$ confidence interval 0.27 to 1.35 ) for $\geqslant 2$ infections $v$ no infections), in agreement with results reported by Martinez et al. ${ }^{14}$ These non-wheezing infections constituted no major risk for subsequent wheeze up to the age of 7 
years, whereas wheezing lower respiratory tract infections showed a strong positive association, supporting our notion of reverse causation.

\section{Association of asthma with other infections}

We observed an inverse association between the total burden of infectious diseases excluding lower respiratory tract infections and subsequent wheeze, asthma, and bronchial hyperreactivity. This protective effect was mainly due to two distinct subgroups of viral infections-runny nose and infections of the herpes type.

The inverse association between runny nose and asthma might be attributable to the arbitrary distinction between infections of the upper and of the lower respiratory tract and simply reflect an asthmatic child's inability to confine symptoms to the nose when the upper respiratory tract is infected. This seems unlikely, however, as there was no difference between children with a family history of atopy and those without in the number of runny nose episodes, and we found a dose-response relation between the number of runny nose episodes and the outcome of asthma at the age of 7 years $(\mathrm{P}=0.028$ for trend $)$. Furthermore, when we included both lower and upper respiratory tract infections in a multivariate logistic regression model both the positive effect of lower respiratory tract infections and the negative effect of recurrent episodes of runny nose on asthma remained significant (data not shown). The observed inverse relation between recurrent runny nose and inhalant sensitisation up to the age of 3 years also indicates an exposure effect rather than a host characteristic.

Indirect support for our notion that repeated episodes of runny nose protect against development of asthma is given by the inverse association of other viral infections, namely viral infections of the herpes type and measles, with asthma-although the small number of measles cases meant that this difference did not reach significance. Results from other studies also suggest a negative association between measles and asthma. ${ }^{1516}$

\section{Implications of results}

Almost all the effects we observed were strongest for infections in the first year of life. Addition of further infections in the second and third years either left the effects largely unchanged or weakened them slightly. This was particularly true for infectious diseases common enough to be analysed solely for the first year of life-that is, lower respiratory tract infections, the total burden of infectious diseases, the total group of viral infections, and the number of runny nose episodes and antibiotic treatments. These findings suggest a window of vulnerability, with an immature immune system being most susceptible to the influence of infections in the first year of life, an idea supported by the results of two recent studies on day care early in life. ${ }^{5} 17$

The mechanisms by which certain viral infections may protect against the development of asthma are not known. The observed dose-response relation between early episodes of runny nose and subsequent development of asthma might reflect the importance of repeated mild infections. This notion is supported by the protective effect of herpes infections, since herpes

\section{What is already known on this topic}

Various markers of infectious burden such as the number of older siblings, day care attendance in early life, and positive serology to orofaecal infections are inversely associated with atopy

However, conflicting evidence exists with respect to the role of infections in early life for the subsequent development of asthma

\section{What this study adds}

The total burden of infection as well as certain viral infections, namely repeated episodes of runny nose and viral infections of the herpes type, before the age of 3 years showed an inverse relation with the development of asthma by the age of 7

The data support the hypothesis that repeated viral infections early in life may stimulate the immature immune system towards the Th1 phenotype, thereby reducing the risk of asthma and atopy

viruses are able to become latent and persist in an apparently inactive state for considerable lengths of time. ${ }^{18}$ However, our data from parental reports could reveal only clinical manifestations of herpes infections, so we do not know whether asymptomatic infections exert a similar protective effect.

\section{Conclusions}

Our results suggest that repeated viral infections other than lower respiratory tract infections early in life may stimulate the immature immune system towards the Th1 phenotype, thereby reducing the risk for the development of asthma up to school age. We found no effect of other types of infectious diseases or of antibiotic treatment on asthma.

Other members of the Multicentre Allergy Study (MAS) Group were Volker Wahn and Marketa Groeger (Düsseldorf), Fred Zepp and Imke Bieber (Mainz), Johannes Forster and Uta Tacke (Freiburg), Carl-Peter Bauer (Gaisach), and Karl E Bergmann (Berlin). We thank all participants in the MAS; the nurses Petra Wagner (Berlin), Gabriele Leskosek (Düsseldorf), Roswitha Mayerl (Munich), and Brigitte Hampel (Mainz); and the statistician Günter Edenharter.

Contributors: SI performed the statistical analysis, interpreted the results, and wrote the manuscript. EvM participated in interpreting the results and writing the paper. SL determined specific IgE concentrations in serum samples. RB developed the questionnaires and undertook the physical examination of the children. BN supervised and performed lung function testing and bronchial challenge tests. CS was responsible for data management of the MAS. UW is the coordinator of the MAS. SI is guarantor for the paper.

Funding: This work was funded by the German Ministry of Education and Research (BMBF), grant-number 01GC9702/0. Competing interests: None declared.

1 Strachan DP. Hay fever, hygiene, and household size. BMJ 1989;299:1259-60.

2 Von Mutius E, Martinez FD, Fritsch C, Nicolai T, Reitmeir P, Thiemann HH. Skin test reactivity and number of siblings. BMJ 1994;308:692-5.

3 Jarvis D, Chinn S, Luczynska C, Burney P. The association of family size with atopy and atopic disease. Clin Exp Allergy 1997;27:240-5.

4 Bodner C, Godden D, Seaton A. Family size, childhood infections and atopic diseases. Thorax 1998;53:28-32.

5 Krämer U, Heinrich J, Wijst M, Wichmann HE. Age of entry to day nursery and allergy in later childhood. Lancet 1998;352:450-4. 
6 Matricardi PM, Rosmini F, Ferrigno L, Nisini R, Rapicetta M, Chionne P, et al. Cross-sectional retrospective study of prevalence of atopy among Italian military students with antibodies against hepatitis A virus. $B M I$ 1997;314:999-1003.

7 Matricardi PM, Rosmini F, Riondino S, Fortini M, Ferrigno L, Rapicetta $\mathrm{M}$, et al. Exposure to foodborne microbes versus airborne viruses in rela$\mathrm{M}$, et al. Exposur to foodborne nicrobes versus airborne viruses in relation to atopy

Sigurs N, Bjarnason R, Sigurbergsson F, Kjellman B, Bjorksten B. Asthma and immunoglobulin $\mathrm{E}$ antibodies after respiratory syncytial virus bronchiolitis: a prospective cohort study with matched controls. Pediatrics 1995;95:500-5.

9 Stein RT, Sherrill D, Morgan WJ, Holberg CJ, Halonen M, Taussig LM, et al. Respiratory syncytial virus in early life and risk of wheeze and allergy by age 13 years. Lancet 1999:354:541-5.

10 Bergmann RL, Bergmann KE, Lau-Schadendorf S, Luck W, Dannemann A, Bauer CP, et al. Atopic diseases in infancy. The German multicenter atopy study (MAS-90). Pediatr Allergy Immunol 1995;5(suppl 1):19-25.

11 Weidtman V. Diagnoseschlüssel für die Pädiatrie. Vol 11. In: Hellbrügge T, ed. Documenta Pädiatrica. Lübeck: Hansesches Verlagskontor, 1982

12 Niggemann B, Illi S, Madloch C, Völkel K, Lau S, Bergmann R, et al
Bronchial histamine challenges in 7 year old children: a PC20FEV1 below $1.0 \mathrm{mg} / \mathrm{ml}$ discriminates between symptomatic and nonsymptomatic children. Eur Respir J (in press).

13 Nicolai T, von Mutius E, Reitmeir P, Wjst M. Reactivity to cold air hyperventilation in normal and in asthmatic children in a survey of 5,697 school children in Southern Bavaria. Am Rev Respir Dis 1993;147:565-72. ciates. Association of non-wheezing lower respiratory tract illnesses in early life with persistently diminished serum IgE levels. Thorax 1995;50:1067-72

15 Farooqi IS, Hopkin JM. Early childhood infection and atopic disorder. Thorax 1998;53:927-32.

16 Shaheen SO, Aaby P, Hall AJ, Barker DJP, Heyes CB, Shiell AW, et al. Measles and atopy in Guinea-Bissau. Lancet 1996;347:1792-6.

17 Ball TM, Castro-Rodriguez JA, Griffith KA, Holberg CJ, Martinez FD, Wright AL. Siblings, day-care attendance, and the risk of asthma and wheezing during childhood. N Engl J Med 2000;343:538-43.

18 Whitley RJ. Herpes simplex viruses. In: Fields BN, Knipe DM, eds Virology. 2nd ed. New York: Raven Press, 1990:1849.

(Accepted 27 November 2000)

\title{
Antibiotic susceptibility of streptococci and related genera causing endocarditis: analysis of UK reference laboratory referrals, January 1996 to March 2000
}

\author{
Alan P Johnson, Marina Warner, Karen Broughton, Dorothy James, Androulla Efsratiou, \\ Robert C George, David M Livermore
}

A combination of penicillin and gentamicin is recommended for streptococcal endocarditis by both the Endocarditis Working Party of the British Society for Antimicrobial Chemotherapy and the American Heart Association, with vancomycin replacing penicillin for those who are allergic to penicillin. ${ }^{2}$ The Public Health Laboratory Service's Antibiotic Resistance Monitoring and Reference Laboratory and Streptococcus and Diphtheria Reference Unit routinely test bacteria referred from cases of endocarditis from a wide range of hospitals, representing about $15 \%$ of all UK isolates from endocarditis. We retrospectively analysed the species distribution and antimicrobial susceptibility of streptococci and related bacteria from patients with endocarditis received over 4.25 years; enterococci have been reviewed previously. ${ }^{3}$

\section{Methods and results}

Isolates from confirmed cases of endocarditis referred between January 1996 and March 2000 were identified from the reference laboratory's database, which provides antibiotic susceptibility as minimum inhibitory concentrations of each antibiotic for each isolate. Isolates were categorised as susceptible or resistant using published criteria. ${ }^{4}$

Data were available for 607 non-duplicate isolates, comprising 26 genera or species, referred from 168 UK hospitals (table). Most (86\%) of the isolates were "viridans" group streptococci, which are documented as the commonest agents of endocarditis. ${ }^{5}$ Five species accounted for over two thirds of the isolates. Among these, $13 \%$ of Streptococcus oralis isolates, $14.5 \%$ of $S$ sanguis, and $5.5 \%$ of $S$ gordonii had reduced penicillin susceptibility (minimum inhibitory concentrations greater than $0.125 \mathrm{mg} / \mathrm{l}$ ), whereas all $S$ bovis type I and $S$ mutans isolates were susceptible. Other species and genera comprised fewer than 20 isolates each, precluding meaningful calculation of percentage resistance. None the less, it was notable that both isolates of Abiotrophia defectiva and six of 15 isolates of $A$ adjacens had reduced susceptibility to penicillin. All isolates of $S$ pneumoniae and Lancefield groups A, B, C, and G streptococci were susceptible to penicillin.

Overall, $88.8 \%$ of the isolates were susceptible to penicillin (minimum inhibitory concentrations $\leqslant 0.125$ $\mathrm{mg} / \mathrm{l}$ ), and minimum inhibitory concentrations of 0.25 $\mathrm{mg} / \mathrm{l}$ were seen for another $4.4 \%$. Minimum inhibitory concentrations of 4-8 mg/l were seen for only seven isolates $(1.2 \%)$. All of the isolates were susceptible to vancomycin and teicoplanin (minimum inhibitory concentrations 0.5 to $2 \mathrm{mg} / \mathrm{l}$ ) and none had high level resistance (minimum inhibitory concentration greater than $2000 \mathrm{mg} / \mathrm{l}$ ) to gentamicin.

\section{Comment}

Although the clinical data available to our reference laboratory are sometimes limited and there is a potential for submission bias, we believe that our analysis is the most comprehensive possible for streptococcal endocarditis. The data confirm the dominance of "viridans" streptococci and indicate that whereas a few $(1.2 \%)$ have substantial penicillin resistance, most remain fully susceptible. Some guidelines advocate that endocarditis of a native valve caused by streptococci that are susceptible to penicillin should be treated for two weeks with penicillin plus gentamicin, provided patients lack thromboembolic disease and cardiac risk factors, have small vegetations, and respond clinically within the first week. ${ }^{1}$ In patients not fulfilling these criteria or with infection of a prosthetic valve, four weeks of penicillin plus gentamicin is recommended. Treatment for at least four weeks is also advocated for

\section{Antibiotic \\ Resistance \\ Monitoring and Reference \\ Laboratory, Central Public Health \\ Laboratory, Colindale, London NW9 5HT \\ Alan P Johnson \\ clinical scientist \\ Marina Warner biomedical scientist Dorothy James data administrator David M Livermore clinical scientist}

continued over

BMJ 2001;322:395-6

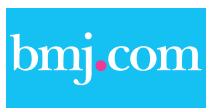

This article is part of the BMJ's randomised controlled trial of open peer review. Documentation relating to the editorial decision making process is available on the BMJ's website 